\title{
Dry/wet climate zoning and delimitation of arid areas of Northwest China based on a data-driven fashion
}

\author{
QingLing GENG ${ }^{1,2,3}$, PuTe WU ${ }^{1,2,3,4^{*}}$, QingFeng ZHANG ${ }^{2,4}$, XiNing ZHAO ${ }^{1,2,3,4}$, YuBao WANG ${ }^{2,4}$ \\ ${ }^{1}$ Institute of Soil and Water Conservation, Chinese Academy of Sciences and Ministry of Water Resources, Yangling 712100, China; \\ ${ }^{2}$ Institute of Water Saving Agriculture in Arid Regions of China, Northwest A\&F University, Yangling 712100, China; \\ ${ }^{3}$ National Engineering Research Center for Water Saving Irrigation at Yangling, Yangling 712100, China; \\ ${ }^{4}$ Northwest A\&F University, Yangling 712100, China
}

\begin{abstract}
The division of arid areas is important in water and land resources management, planning and for a long-term agricultural, economic and social planning. Northwest China (NW) dominates the main arid areas in China. There is thus a need to adopt adequate concepts relative to the scope of arid areas of NW China and identify its climate types and characteristics. In this study, we analyzed climatic data over the last 30 years (1981-2010) from 191 stations in three provinces and three autonomous regions of NW China. The factor-cluster analysis technique (FC), an objective and automated method was employed to classify the dry/wet climate zones. The traditional methods with predefined thresholds were adopted for providing a comparison with FC. The results showed that the wet/dry climate zones by FC were mainly distributed along mountains, rivers and desert borders. Climate-division boundaries relied heavily on the major terrain features surrounding the grouped stations. It also showed that the climate was dry in the plain sandy areas but relatively wet in the high mountain areas. FC method can reflect the climate characteristics more fully in NW China with varied and complicated topography, and outperform the traditional climate classifications. Arid areas of NW China were defined as four climate types, including five resultant classes in FC classifications. The Qinling and Da Hinggan Mountains were two important boundaries, besides main administrative boundaries. The results also indicated that there are some differences between two traditional classifications. The precipitation moved and fluctuated to an extent, which confirmed that climate change played an important role in the dry/wet climate zoning, and the boundaries of dry/wet climate zones might change and migrate with time. This paper is expected to provide a more in-depth understanding on the climate characteristics in arid areas of NW China, and then contribute to formulate reasonable water and land management planning and agricultural production programs.
\end{abstract}

Keywords: arid areas; classifications; climate zoning; factor-cluster analysis

Citation: QingLing GENG, PuTe WU, QingFeng ZHANG, XiNing ZHAO, YuBao WANG. 2014. Dry/wet climate zoning and delimitation of arid areas of China based on a data-driven fashion. Journal of Arid Land, 6(3): 287-299. doi: 10.1007/s40333-013-0206-7

Drought and water scarcity have a significant effect on agricultural, ecological and economic development. They have been recognized as global issues (Logan et al., 2010; Mishra and Singh, 2010). According to the statistics from UNESCO in 1977, arid and semi-arid regions span more than 50 countries and regions in the world. The total area accounted for $34.9 \%$ of the global terrestrial sphere. In China, they cover above half of total land area. Currently, arid areas are still expanding and aridity degree is worsening ( $\mathrm{Li}$ et al., 2004; Liu and Diamond, 2005; Fu and Ma, 2008). Information on regional drought characteristics can provide critical information for adequate water resource management (Hisdal and Tallaksen, 2003). Bernardo et al. (2006) suggested that climate must be examined as it is a decisive factor for ensuring proper irrigation management to provide adequate water supply for crop development. Therefore, arid areas have become

\footnotetext{
*Corresponding author: PuTe WU (E-mail: gjzwpt@vip.sina.com) Received 2013-03-30, revised 2013-08-17, accepted 2013-09-02 (C) Xinjiang Institute of Ecology and Geography, Chinese Academy of Sciences, Science Press and Springer-Verlag Berlin Heidelberg 2014
} 
one of the most important subjects in the fields of climatological, geographical, ecological and agricultural researches, especially in the context of climate change.

Northwest China is located in the inner center of Eurasia. It dominates the most of the arid areas in China and is also an important reserve base of food production. The identification of classifications and characteristics of arid areas of NW China is an essential need for economic development and ecological environment construction. The original definition of arid areas of NW China originated from the comprehensive physical regionalization of China, which can date back to the 1950s (Luo, 1954). The establishment of three large physiographical regions by Huang (1959) formed a milestone in the field of physical regionalization in China and promoted the understanding on arid areas of NW China. Following this, many scholars from different fields, different aspects and with different research purposes have redefined the geographic regions of China, as shown in Table 1. Regionalization schemes can be summarized as three types: seven basic physical divisions (Luo, 1954; Zhang et al., 1956), three large physical divisions (Huang, 1959; Zhao, 1983; Xi et al., 1984; Li, 1987) and eight physical divisions (CAS, 1959; Ren and Yang, 1961). The dry/wet climate zoning was an important aspect in these regionalization schemes. However, there are many differences of opinion on the scope of arid areas of NW China, mainly caused by

Table 1 Main achievements in the regionalization field in China

\begin{tabular}{|c|c|c|c|}
\hline Source & Geographic region & Criteria and index & Scope of arid areas \\
\hline Luo, 1954 & $\begin{array}{l}\text { Northeast China, North China, } \\
\text { Kangdian, Central China, } \\
\text { South China, Qinghai-Tibet, } \\
\text { Inner Mongolia-Xinjiang }\end{array}$ & $\begin{array}{l}\text { Thermal index: temperature; } \\
\text { dry/wet climate index: precipitation, air } \\
\text { relative humidity. }\end{array}$ & $\begin{array}{l}\text { Inner Mongolia-Xinjiang Plateau and Qaidam } \\
\text { Basin. Its eastern areas are the Tibet Plateau, the } \\
\text { Loess Plateau, the north of Hebei and so on. }\end{array}$ \\
\hline Huang, 1959 & $\begin{array}{l}\text { East China monsoon region, } \\
\text { Inner Mongolia-Xinjiang Pla- } \\
\text { teau, Qinghai-Tibet Plateau }\end{array}$ & $\begin{array}{l}\text { First level index: thermal condition; } \\
\text { second level index: water condition } \\
\text { (aridity: humid }(<1.0) \text {, sub-humid } \\
(1.0-1.5) \text {, semiarid }(1.5-2.0) \text {, } \\
\text { arid }(>2.0)) \text {. }\end{array}$ & $\begin{array}{l}\text { The north of Qinghai-Tibet Plateau and Loess } \\
\text { Plateau, plus Xinjiang and the west of Inner } \\
\text { Mongolia, covering } 27.3 \% \text { of China. }\end{array}$ \\
\hline $\begin{array}{l}\text { Ren and } \\
\text { Yang, } 1961\end{array}$ & $\begin{array}{l}\text { Northwest China, Northeast } \\
\text { China, North China, Central } \\
\text { China, South China, Southwest, } \\
\text { Inner Mongolia, Qinghai-Tibet }\end{array}$ & $\begin{array}{l}\text { Temperature, topography, soil, aridity } \\
\text { (humid }(<1.0) \text {, sub-humid }(1.0-1.5) \text {, } \\
\text { semiarid }(1.5-2.0) \text {, arid }(>2.0)) \text {. }\end{array}$ & $\begin{array}{l}\text { Xinjiang, Qaidam Basin, Alxa Plateau and the } \\
\text { Hexi Corridor in Gansu }\end{array}$ \\
\hline Zhao, 1983 & $\begin{array}{l}\text { East China monsoon region, } \\
\text { Northwest arid area, } \\
\text { Qinghai-Tibet Plateau }\end{array}$ & $\begin{array}{l}\text { Active accumulated temperature, } \\
\text { altitude, aridity (humid }(<1.0) \text {, } \\
\text { sub-humid }(1.0-1.5) \text {, semiarid }(1.5-2.0) \text {, } \\
\text { arid }(>2.0)) \text {, precipitation }(\text { semiarid } \\
(200-400 \mathrm{~mm}) \text {, arid }(<200 \mathrm{~mm})) \text {. }\end{array}$ & $\begin{array}{l}\text { Eastern boundary: aridity index } \geq 1.2-1.5 \text {; } \\
\text { northern boundary: Kunlun, Altun and Qilian } \\
\text { mountains, including the Inner Mongolia steppe } \\
\text { and the northwest desert area, covering } 30 \% \text { of } \\
\text { China. }\end{array}$ \\
\hline $\begin{array}{l}\text { Xi et al., } \\
1984\end{array}$ & $\begin{array}{l}\text { East China monsoon region, } \\
\text { Northwest arid area, } \\
\text { Qinghai-Tibet Plateau }\end{array}$ & $\begin{array}{l}\text { Temperature, water condition } \\
\text { (aridity and precipitation), vegetation, } \\
\text { geomorphology, soil. }\end{array}$ & $\begin{array}{l}\text { The west of Da Hinggan Mountains, the north of } \\
\text { Kunlun, Altun and Qilian mountains, covering } \\
29.8 \% \text { of China. }\end{array}$ \\
\hline Zhang, 1956 & $\begin{array}{l}\text { Northeast China, North China, } \\
\text { Kangdian, Central China, South } \\
\text { China, Inner Mongolia-Xinjiang, } \\
\text { Qinghai-Tibet }\end{array}$ & $\begin{array}{l}\text { First level index: wetness index, } \\
\text { annual precipitation; } \\
\text { second level index: temperature }\end{array}$ & $\begin{array}{l}\text { Most of Xinjiang, the Hexi Corridor and the } \\
\text { Inner Mongolia Plateau }\end{array}$ \\
\hline CAS, 1959 & $\begin{array}{l}\text { Northeast China, North China, } \\
\text { Central China, South China, } \\
\text { Gansu-Xinjiang, Kangdian, } \\
\text { Inner Mongolia, Qinghai-Tibet }\end{array}$ & $\begin{array}{l}\text { Thermal belts as east-west border; arid- } \\
\text { ity as south-north border (humid }(<1.0) \text {, } \\
\text { sub-humid }(1.0-1.5) \text {, semiarid }(1.5-4.0) \text {, } \\
\text { arid }(4.0-16.0) \text {, extreme arid }(>16.0) \text { ) }\end{array}$ & $\begin{array}{l}\text { The north of Kunlun, Altun and Qilian moun- } \\
\text { tains, the west of Helan Mountains, including } \\
\text { Xinjiang, the west of Bayannur, Minqin and the } \\
\text { Hexi corridor. }\end{array}$ \\
\hline Chen, 1982 & $\begin{array}{l}\text { Thermal belts, Climate large } \\
\text { region, Climate region }\end{array}$ & $\begin{array}{l}\text { First level index: } \geq 10^{\circ} \mathrm{C} \text { of } \\
\text { accumulated temperature and days; } \\
\text { second level index: aridity and } \\
\text { precipitation (humid }(<1.0 \text {, } \\
>800-900 \mathrm{~mm}) \text {, sub-humid }(1.0-1.6 \text {, } \\
450-900 \mathrm{~mm}) \text {, semiarid }(1.6-3.5, \\
200-500 \mathrm{~mm}) \text {, arid }(3.5-16.0, \\
<200-250 \mathrm{~mm}) \text {, extreme arid }(>16.0))\end{array}$ & $\begin{array}{l}\text { No specific explanations on the arid zone of } \\
\text { Northwest China. }\end{array}$ \\
\hline Li, 1987 & $\begin{array}{l}\text { East China monsoon region, } \\
\text { Northwest arid area, } \\
\text { Qinghai-Tibet Plateau }\end{array}$ & $\begin{array}{l}\geq 0^{\circ} \mathrm{C} \text { of accumulated temperature, } \\
\text { wind speed, annual precipitation. }\end{array}$ & $\begin{array}{l}\text { The east of Da Hinggan Mountains, crossing } \\
\text { Ulan Ho-Tongliao-north Chifeng-Datong- } \\
\text { Yulin-North Huining-South Lanzhou, } \\
\text { covering } 28.2 \% \text { of China. }\end{array}$ \\
\hline
\end{tabular}


the selection of different indices and their predefined thresholds. The indices used to locate the arid areas of NW China include two indices of precipitation and aridity. They can be regarded as a "rule-driven" strategy in which the climate types are first defined using selected measures and then used to determine the classification of each locale for which the appropriate data are available, yielding the regionalization (Fovell, 1997). However, the process was partly subjective since thresholds were often predefined on the basis of discernible changes in some important components of the global ecosystem (e.g. alignment with major watersheds, agricultural administrative districts and geographic convenience) and expert judgment (Kostopoulou and Jones, 2007; Abatzoglou et al., 2009; Jacobeit, 2010), so that the scope of arid areas varied with indices and their rules, and also research purposes.

To avoid the direct specification of classification rules, we employed an objective and automated method for the dry/wet climate zoning in this paper. The method applied a "data-driven" fashion to classify the climate zones, often utilizing some forms of multivariate statistical techniques, e.g. cluster algorithm (Fovell, 1997). In contrast, the implementation of the technique has allowed to classify climate without predefined thresholds by grouping individual objects (e.g. weather stations) into self-generating classes according to particular statistical criteria (Jacobeit, 2010), so that it can be widely used in climate classifications, such as diverse climates in Turkey (Unal et al., 2003) and Alaska of the USA (Bieniek et al., 2012). It was also applied to develop climate divisions for Saudi Arabia by combining with the factor analysis technique (Ahmed, 1997).

In addition, in early weather-classification studies only experiences from individuals were available, making studies more difficult, subjective and inaccurate (Kostopoulou and Jones, 2007). Even if the observed data were applied, they were mainly from before the 1980s (Zheng et al., 2010). However, the climate had changed since the 1980s (Shi et al., 2006; Qian and Qin, 2007; Fang et al., 2009). More detailed meteorological information can be provided by many organizations currently. Quantitative and objected techniques, such as Geographic Information System (GIS) and Remote Sensing (RS), also experienced fast development in the last two decades, making data ac- quisition and subsequent quantification of natural resources easier, and reducing time and costs as well (Castillo-Rodríguez et al., 2010). Therefore, it has become more feasible and necessary to re-recognize the regional physio-geographical system and dry/wet climate characteristics (Zhang and Li, 1999; Zheng et al., 2010).

This study identified dry/wet climatic zones and examined the climate distribution characteristics based on the factor-cluster analysis. The traditional classifications (precipitation and aridity indices) with predefined thresholds were employed for providing a comparison with FC.

\section{Study area and methods}

\subsection{Study area}

In this paper, the study area includes Xinjiang, Ningxia, and Inner Mongolia autonomous regions, Shaanxi, Gansu and Qinghai provinces. The topography is complicated and changeable, and mountains range across its length and breadth in this region. Distance from the coast and terrains which make moisture difficult to reach the region are the major factors affecting the climatic conditions and geomorphic features (Zhang and $\mathrm{Su}, 1993$ ). In addition, high altitude caused by uplift of the Qinghai-Tibet Plateau severely obstructed the movement of the water vapor (Zhang et al., 2000). As a result, it is one important part of inland arid regions in Asia. Featured by a unique morphological complexity consisting of mountains, hills, plateaus, basins and plains, the landscape of the region therefore generates diverse biomes (forests, grasslands, deserts and oases) (Zhao et al., 2011). High mountains like Tianshan Mountains, Kunlun Mountains, Qilian Mountains and Da Hinggan Mountains block atmospheric circulation and thus create vast deserts, basins and plateaus in the rain shadow, such as Tengger Desert, Badain Jaran Desert, the Tarim Basin, the Junggar Basin, the Qaidam Basin, and Mongolian Plateau (Shi et al., 2006; Yang et al., 2008; Fang et al., 2009). Meanwhile, the unique topography enables this region to reserve rich melt water resources. The surface runoff flowing out of mountain mouthS becomes the only water source available for the middle and lower reaches of inland river basins (Wang and Cheng, 2000). 
The regional economy relies primarily on agriculture. However, water scarcity has a significant restriction on agricultural production. Meanwhile, the amount of reserved arable land is difficult to increase also due to the impact of water scarcity (Yang et al., 2010), which as a result, restricts the economic and social development. In comparison with other regions in China, the economy in most of NW arid areas is relatively undeveloped and the ecological environment is highly vulnerable (Yang et al., 2008). Furthermore, water usage is highly inefficient, although there are extensive irrigation systems in this region. The annual average water usage for irrigation is much higher than the national average of $6,000 \mathrm{~m}^{3} / \mathrm{hm}^{2}$. In some parts, particularly in the autonomous region of Ningxia, the annual irrigation water usage is up to $22,215 \mathrm{~m}^{3} / \mathrm{hm}^{2}$, but more than half of this water is lost to leakage before reaching farmers' fields (Yang et al., 2008). Therefore, it is necessary to gain a more detailed understanding of dry/wet climate in the region to formulate reasonable water and land management planning and guide agricultural production.

\subsection{Data}

Meteorological data were obtained from the China Meteorological Data Sharing Service System (http: //cdc. cma. gov.cn). The basic data for the last 30 years (1981-2010) were extracted from 213 weather stations in three provinces and three autonomous regions. These data include the mean air temperature (T), maximum and minimum air temperature $\left(\mathrm{T}_{\max }\right.$ and $T_{\text {min }}$ ), relative humidity $\left(R_{h}\right)$, wind speed $(V)$, sunshine duration $\left(\mathrm{S}_{\mathrm{h}}\right)$, precipitation $\left(\mathrm{P}_{\mathrm{m}}\right)$ and air pressure $\left(\mathrm{P}_{\mathrm{a}}\right)$ at a monthly time step.
According to the principle of dominant factors, we selected precipitation and evapotranspiration which characterize the surface water budget, and air relative humidity reflecting dry and wet conditions of the atmosphere. For the principle of serving for agriculture, precipitation variability and annual temperature range which respectively impact the stability of agriculture production and planting structure were also chosen. Their annual average values were calculated based on the above monthly data. In addition, the longitude, latitude and altitude of each station were provided for the spatial interpolation by using the Kriging method. Stations for which the missing data rate was greater than 5\% were rejected. We finally determined 191 sample points (Fig. 1). Basic statistics of monthly data and total number of missing values after omitting 22 stations are shown in Table 2. Figure 1 presented the location of the study area and distribution of weather stations. Here, remote sensing data comes from the EOS/MODIS satellite image map of China in 2002.

\subsection{Methodology}

\subsubsection{Factor analysis (FA)}

The main purpose of FA method is to extract and integrate the overlapped information so as to realize the dimension reduce among original variables. Variables should have a strong correlation with each other. Accordingly, two required basic assumptions, i.e. the Kaiser-Meyer-Olkin (KMO) statistic and Bartlett's test of sphericity, must be verified before using the FA. The KMO, which is the sampling adequacy testing whether the partial correlations among items are small, was performed so as to decide whether each variable is appropriate for FA (Um et al., 2011). The approved

Table 2 Basic statistics of monthly data and total number of missing values after omitting 22 stations

\begin{tabular}{lrrrrrrr}
\hline Variable & Mean & Maximum & Minimum & Median & St. Dev. & Missing & Percent (\%) \\
\hline $\mathrm{T}\left({ }^{\circ} \mathrm{C}\right)$ & 6.4 & 33.9 & -33.9 & 7.3 & 12.2 & 937 & 1.36 \\
$\mathrm{~T}_{\max }\left({ }^{\circ} \mathrm{C}\right)$ & 13.4 & 41.3 & -27.9 & 14.3 & 12.1 & 937 & 1.36 \\
$\mathrm{~T}_{\min }\left({ }^{\circ} \mathrm{C}\right)$ & 0.4 & 27.2 & -40.4 & 1.4 & 12.0 & 937 & 1.36 \\
$\mathrm{R}_{\mathrm{h}}(\%)$ & 53.7 & 93.0 & 13.0 & 53.0 & 15.0 & 939 & 1.37 \\
$\mathrm{~V}(\mathrm{~m} / \mathrm{s})$ & 2.4 & 12.9 & 0.0 & 2.2 & 1.2 & 940 & 1.37 \\
$\mathrm{~S}_{\mathrm{h}}(\mathrm{h})$ & 230.7 & 403.9 & 4.4 & 232.3 & 56.5 & 944 & 1.37 \\
$\mathrm{P}_{\mathrm{m}}(\mathrm{mm})$ & 24.4 & 689.9 & 0.0 & 8.3 & 37.8 & 936 & 1.36 \\
$\mathrm{P}_{\mathrm{a}}(\mathrm{Pa})$ & $85,156.7$ & $103,620.0$ & $56,980.0$ & $87,640.0$ & $9,780.3$ & 939 & 1.37 \\
\hline
\end{tabular}

Note: 'Missing' denotes the total number of missing values for 191 stations and 'Percent' denotes the percentage of missing values. 
range of values of $\mathrm{KMO}(0.7$ to 1.0$)$ indicates the sample size sufficiency, though realistically it should exceed 0.80 if the results of the FA are to be more reliable (Sun and Yu, 2012). The correlation coefficient and the significant level of each variable from an examination of the correlation matrix are shown in Table 3. All of the variables except annual temperature range $\left(T_{r}\right)$ showed high values of correlation coefficients over the entire matrix. However, the significant level of the correlation coefficient between $\mathrm{T}_{\mathrm{r}}$ and $\mathrm{H}$ exceeds the standard of the significant level $(a<0.05)$ and thus, it is inadequate to apply $T_{r}$. Consequently, the $T_{r}$ was removed. Meanwhile, the KMO statistic increased to 0.744 after discarding the $\mathrm{Tr}$, which is up to the middling standard (Kaiser and Rice, 1974) and is more appropriate for the FA. The Bartlett's test is to give the information whether the correlation matrix is an identity matrix. Very small values of significance (below $0.05)$ for Bartlett's test demonstrate that the dataset is not an identity matrix and it is appropriate for the FA, whereas higher values ( 0.1 or above) indicate it is inappropriate (Um et al., 2011). The model in this

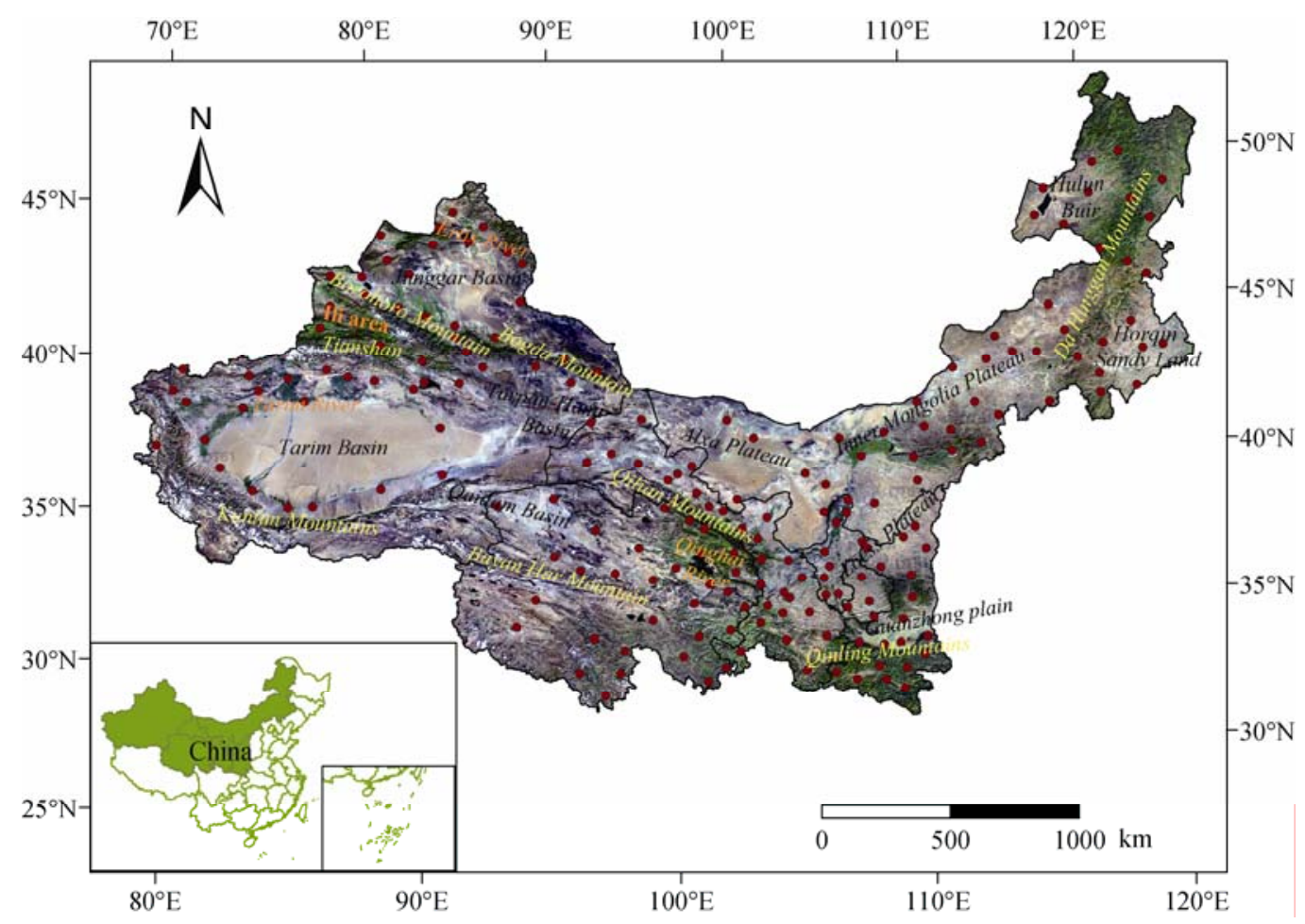

Fig. 1 Location of the study area and distribution of weather stations

Table 3 Correlation matrix for the FA

\begin{tabular}{clccccc}
\hline & & $\mathrm{P}$ & $\mathrm{ET}$ & $\mathrm{R}$ & $\mathrm{H}$ & $\mathrm{T}_{\mathrm{r}}$ \\
\hline \multirow{5}{*}{ Correlation coefficient } & $\mathrm{P}$ & 1.000 & -0.615 & -0.683 & 0.725 & -0.496 \\
& $\mathrm{ET}$ & -0.615 & 1.000 & 0.565 & -0.764 & 0.232 \\
& $\mathrm{R}$ & -0.683 & 0.565 & 1.000 & -0.537 & 0.334 \\
& $\mathrm{H}$ & 0.725 & -0.764 & -0.537 & 1.000 & -0.155 \\
& $\mathrm{~T}_{\mathrm{r}}$ & -0.496 & 0.232 & 0.334 & -0.155 & 1.000 \\
& $\mathrm{P}$ & - & 0.000 & 0.000 & 0.000 & 0.000 \\
& $\mathrm{ET}$ & 0.000 & - & 0.000 & 0.000 & 0.000 \\
Significance (1-tailed) & $\mathrm{R}$ & 0.000 & 0.000 & - & 0.000 & 0.000 \\
& $\mathrm{H}$ & 0.000 & 0.000 & 0.000 & - & 0.013 \\
& $\mathrm{~T}_{\mathrm{r}}$ & 0.000 & 0.000 & 0.000 & 0.013 & - \\
\hline
\end{tabular}

Note: $\mathrm{P}$ is the annual precipitation, ET is the annual potential evapotranspiration calculated by Penman-Monteith method (Allen et al., 1998), R is the precipitation variability, and $\mathrm{H}$ is the mean relative humidity. 
Table 4 Summary of factor analysis

\begin{tabular}{ccccccc}
\hline \multirow{2}{*}{ Component } & \multicolumn{3}{c}{ Initial eigenvalues } & & \multicolumn{2}{c}{ Component score coefficient matrix } \\
\cline { 2 - 4 } \cline { 3 - 4 } & Total & $\begin{array}{c}\text { Percentage of variance } \\
(\%)\end{array}$ & $\begin{array}{c}\text { Cumulative variance } \\
(\%)\end{array}$ & Variable & & Component 1 \\
\hline 1 & 2.949 & 73.715 & 73.715 & $\mathrm{P}$ & 0.299 \\
2 & 0.532 & 13.311 & 87.026 & $\mathrm{ET}$ & -0.291 \\
3 & 0.337 & 8.434 & 95.461 & $\mathrm{R}$ & -0.272 \\
4 & 0.182 & 4.539 & 100 & $\mathrm{H}$ & 0.301 \\
\hline
\end{tabular}

paper satisfied the standard of the significant level $(\alpha<0.05)$.

The Kaiser criterion and Scree-test were used to address the number of factor question. Accordingly, all principal components (PCs) with eigenvalues of $>1.0$ were extracted. Such an eigenvalue was generally employed for FA in order to estimate the appropriate number of factors (Kim and Mueller, 1978; Um et al., 2011). The same purpose can be achieved by a break point with the values of variance of components in a Scree-test plot. As such, one component was determined (Fig. 2; Table 4). The orthogonal VARIMAX NORMALIZED rotation was used for FA to improve the interpretation of the unrotated PCs results (Overall and Klett, 1972). The standardized PC scores were calculated using the regression method.

From Table 4, we can know that the $F$ value is positively correlated with precipitation and air relative humidity but negatively correlated with precipitation variability and evapotranspiration. That is, the lower the $F$ value, the drier the climate. Meanwhile, we can know that there is the similar weight (close to 0.3) among the four elements. It indicates that they have the similar effect on the dry/wet climate. The linear

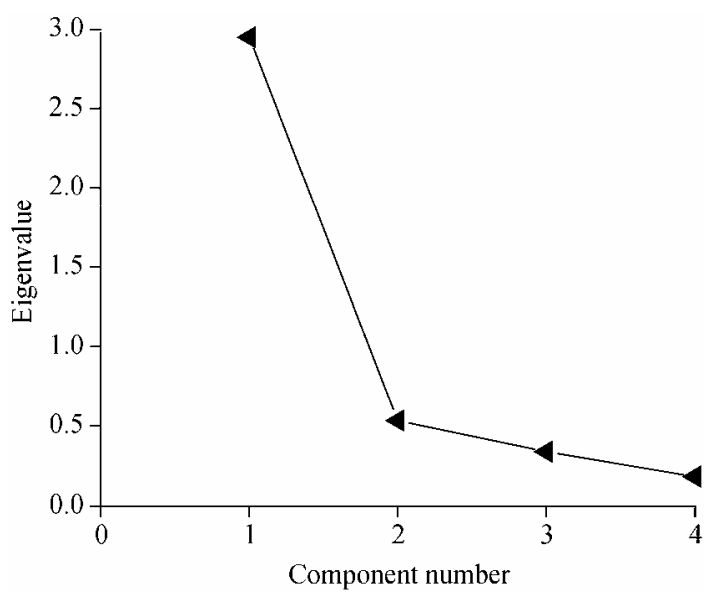

Fig. 2 Scree plot of eigenvalues to determine component numbers model of the resultant factor was expressed as follows:

$$
F=0.299 P-0.291 E T-0.272 R+0.301 H \text {. }
$$

\subsubsection{Cluster analysis (CA)}

CA method is a standard method of statistical multivariate analysis (Malekinezhad et al., 2011). It is used to assign cases to groups (clusters), and the withingroup members share certain common properties (Zhang et al., 2011). In this study, we applied the hierarchical cluster technique, an ideal method for the exploratory stage of research (Unal et al., 2003; Modarres and Sarhadi, 2011), classify the wet/dry climate homogeneous regions. The resultant factor scores by using FA are taken as an input in the CA to obtain climatic regions. The method has been employed for climatic classification of Saudi Arabia (Ahmed, 1997) and the regionalization of Iran's precipitation climate (Dinpashoh et al., 2004). In this paper, seven resultant regions were presented. The value of climate classes was defined from big to small, depending on the climatic characters from arid to humid.

\subsubsection{GIS spatial analysis}

Geographic Information Systems (GIS) is a technique comprehensively processing and analyzing the geo-spatial data by applying the theories of systems engineering and information science. It contains multi-function analysis modules, including data collection and edit, mapping function, spatial analysis, the establishment of DEM and so on. The technique permits the fast integration and representation of different attributes to delineate environmental units (Castillo-Rodríguez et al., 2010). In this paper, we delineated the dry/wet climate units by applying the geo-statistics module, in which the Kriging method was used to spatial interpolation analysis. The detailed steps combined FC with GIS are shown in Fig. 3. 


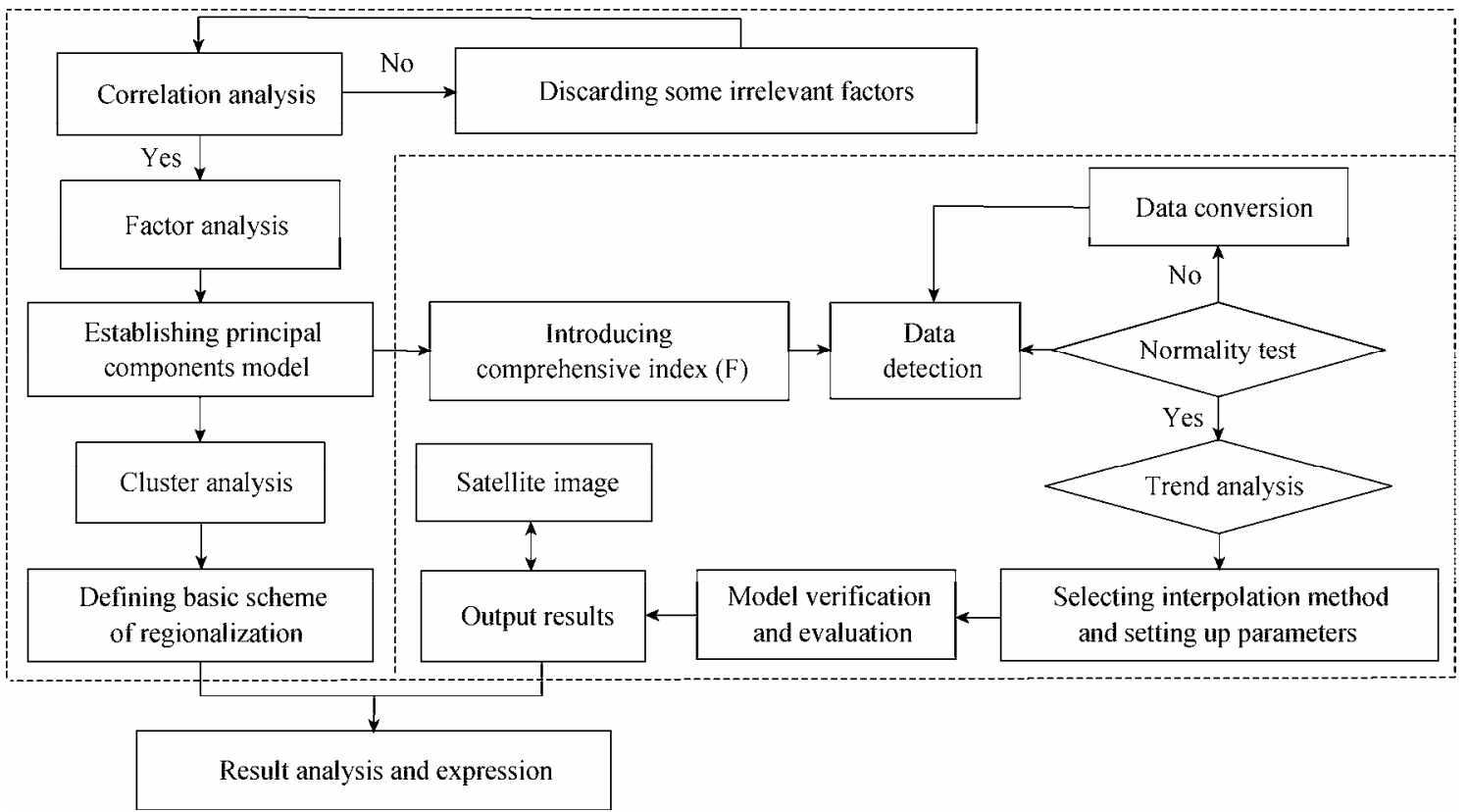

Fig. 3 Flow chart of the methodology proposed for the dry/wet climate zoning

\section{Results}

\subsection{Spatial characteristics of dry/wet climate clas- sifications}

Seven classes were identified according to the result from FC analysis. The $F$ value of factor scores progressively decreased from class 1 to class 7 , the climate characteristics following from humid to arid (Fig. 4). Divisional boundary lines were drawn by identifying major terrain features. These boundaries were well in agreement with natural barriers between regions. The major topographies, including the Kunlun Mountains in Class 7, Tarim River, Bogda Peak and Burhan Budai Mountains in Class 6, Tianshan Mountains, Borohoro Mountains, Ertix River and Qilian Mountains in Class 5, the delimitation between Loess Plateau and Guanzhong Plain in Class 4, and the Qinling Mountains in Class 2, are the important boundaries of climate zoning.

In terms of spatial distribution of climate zones, region 7 included the most part of Tarim Basin, the east of Xinjiang (Turpan-Hami Basin), the west of Qaidam Basin and Alxa Plateau of Inner Mongolia. The precipitation is less than $50 \mathrm{~mm}$ in most areas. The evapotranspiration is generally above $1,200 \mathrm{~mm}$, while above $1,500 \mathrm{~mm}$ in Alxa Plateau. Air relative humidity is lower than $35 \%$. The precipitation vari- ability is above $35 \%$, and even up to $60 \%$ in some areas. It is the driest region, and forms the core area of arid climate in China.

Followed by region 7, region 6 extends outward to the edge areas of Tarim Basin, Qaidam Basin and Alxa Plateau. The arid characteristics mitigate to some extent. The precipitation is in the range of $50-150 \mathrm{~mm}$, and its variability is about $35 \%$. Air relative humidity ranges from $35 \%$ to $50 \%$. The evapotranspiration still varies between about $1,200 \mathrm{~mm}$ and $1,500 \mathrm{~mm}$. It can be considered the transition area from extreme arid to arid climate. The landscape feature is similar to that in region 7. Desert and desert steppe are still the main

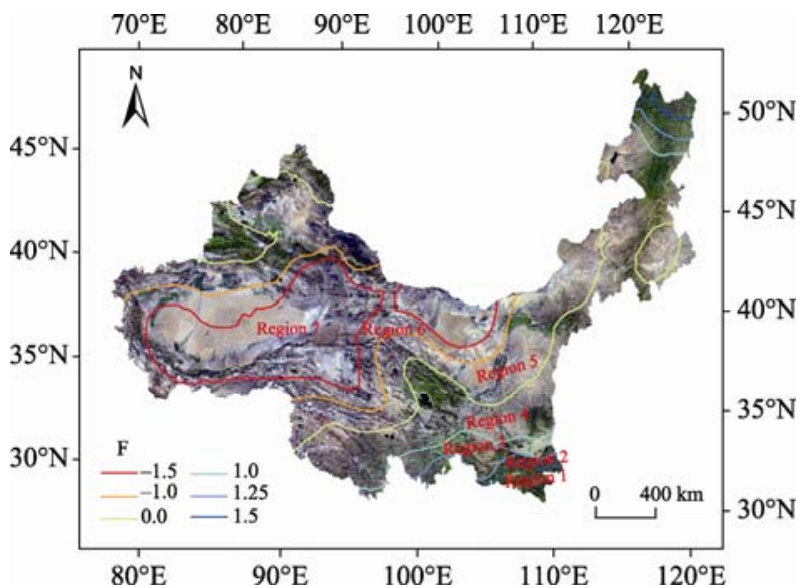

Fig. 4 Map of climate classes according to FC 
geomorphologic types.

Relatively, region 5 shows a significant difference with the above two classes. The precipitation ranges from $150 \mathrm{~mm}$ to $300 \mathrm{~mm}$. The evapotranspiration decreases to about $1,100 \mathrm{~mm}$. The precipitation variability also has an obvious decline. Air relative humidity is about $45 \%$. It mainly covers the middle of Inner Mongolia Plateau, Ningxia Plain, Hexi Corridor of Gansu, the middle of Qinghai, the Junggar Basin in the northwest of Xinjiang, and the regions located between Tianshan Mountains and Tarim River. Besides, Horqin Sandy Land in Inner Mongolia is also located in region 5. Animal husbandry is relatively well developed in this region. Agriculture is only developed under the condition of irrigation. Ecological environment is relatively fragile.

Region 4 involves a few unique geographic subregions, including the Loess Plateau of northern Shaanxi, the loess hilly region of central Gansu, the district around Qinghai Lake, the upper reaches of Huangshui Valley, the source regions of Yangtze and Yellow Rivers in Qinghai, the Ili River Valley and Altai Area of Xinjiang, also the Hulun Buir and east of the Inner Mongolia Plateau. The precipitation is between $300 \mathrm{~mm}$ and $500 \mathrm{~mm}$, and the precipitation variability is within $30 \%$. The evapotranspiration is in the range of $900-1,000 \mathrm{~mm}$. Air relative humidity ranges from $50 \%$ to $65 \%$. This region is the important part of farming-pastoral zone in China (Liu et al., 2011) and also one part of semi-dry land farming (Shan, 2007). Agriculture enjoys certain development.

Region 3 mainly includes Guanzhong Plain of Shaanxi and the mountainous region of southern Gansu. The precipitation is in the range of 500-700 mm. Air relative humidity was about $65 \%$. The precipitation variability is low, and is smaller in the plateau than in the plain. It has relatively flat terrains and a flourishing agriculture. Agriculture plays a dominant role in the region.

The range of Qinling Mountains forms a separate class, the region 2, while the south of Qinling Mountains is region 1 . The climate is relatively humid and precipitation is rich, which is more than $900 \mathrm{~mm}$ in region 1. It is the most humid area in the whole study area. The characteristics of vegetation and agricultural production show a significant difference with those of other regions. Paddy field begins to predominate in the type of the cropland, instead of dry-land.

\subsection{Climate zoning comparison with traditional methods}

The dry/wet climate zonings by applying traditional climate classification methods were compared with the resultant regions of the factor-cluster analysis obtained in the present study. Precipitation and aridity indices are two of the most common and traditional indicators in the dry/wet climate classifications, and thus adopted for the comparison. All the methods considered in this study have the advantage of taking climate elements as a base to obtain climate regions. They do not consider geographic regions and then deduce dry/wet climate regions (Ahmed, 1997). The classification thresholds of aridity index and precipitation used in this paper followed the common rules from climate regionalization of China as in abovementioned achievements. Several important thresholds for precipitation and aridity index were given in the process of classifications (Figs. 5 and 6).

Aridity index was defined as the ratio of the annual precipitation $(\mathrm{P})$ to potential evapotranspiration $\left(\mathrm{ET}_{0}\right)$ totals (UNEP, 1992). The equation is as follows:

$$
A I=\frac{E T_{0}}{P}
$$

where, $\mathrm{ET}_{0}$ is expressed by the Penman-Monteith method which was revised and recommended as the sole standard by FAO (Allen et al., 1998).

$$
E T_{0}=\frac{0.408 \Delta\left(R_{n}-G\right)+\gamma \frac{900}{T+273} u_{2}\left(e_{s}-e_{a}\right)}{\Delta+\gamma\left(1+0.34 u_{2}\right)} .
$$

Where, $\mathrm{ET}_{0}$ is potential evapotranspiration $(\mathrm{mm} / \mathrm{d}), \mathrm{R}_{\mathrm{n}}$ is the net radiation at the crop surface $\left(\mathrm{MJ} /\left(\mathrm{m}^{2} \cdot \mathrm{d}\right)\right), \mathrm{G}$ is the soil heat flux density $\left(\mathrm{MJ} /\left(\mathrm{m}^{2} \cdot \mathrm{d}\right)\right)$, $\mathrm{T}$ is the air temperature at 2-m height $\left({ }^{\circ} \mathrm{C}\right), \mathrm{u}_{2}$ is the wind speed at $2-\mathrm{m}$ height $(\mathrm{m} / \mathrm{s}), \mathrm{e}_{\mathrm{s}}$ is the saturation vapor pressure $(\mathrm{kPa}), \mathrm{e}_{\mathrm{a}}$ is the actual vapor pressure $(\mathrm{kPa}), \mathrm{e}_{\mathrm{s}}-\mathrm{e}_{\mathrm{a}}$ is the saturation vapor pressure deficit $(\mathrm{kPa}), \Delta$ is the slope vapor pressure curve $\left(\mathrm{kPa} /{ }^{\circ} \mathrm{C}\right)$ and $\gamma$ is the psychrometric constant $\left(\mathrm{kPa} /{ }^{\circ} \mathrm{C}\right)$.

According to Fig. 5, the overall agreement in the wet/dry climate regime can be considered good between the FC analysis and aridity index. When looking across classes, we can find that region 6 matches with the climate zone by aridity index of 16.0 , region 5 with 4.0, region 4 with 2.0, and region 3 with 1.5. However, there are still some discrepancies in region 5 , mainly occurring in the Ili area located in the north- 
west of Xinjiang which is called a 'humid island' in arid regions (Zhang, 2006) and the Horqin Sandy Land in the northeast of Inner Mongolia which is one of the four largest desertification regions in China (Zhang et al., 2012). In addition, the regions in class 7 bearing the driest climate, where the precipitation is less than $50 \mathrm{~mm}$, is classified as an individual class, and no climate zone in climate classifications corresponding to aridity index match with it. The north and south of Qinling Mountains were respectively divided into as region 3 and region 1 according to the $\mathrm{FC}$ method, and this mountain range formed a particular climate class (i.e. class 2), which showed another distinction with the zoning by aridity index.

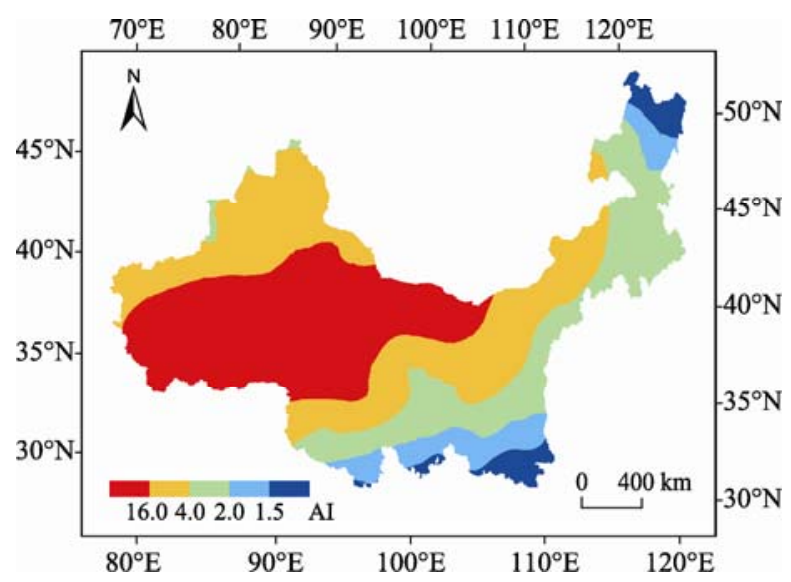

Fig. 5 The dry/wet climate zoning for China corresponding to aridity index (AI)

Figure 6 is the climate zoning corresponding to precipitation. By contrast, the distribution of precipitation shows some similarities and differences with

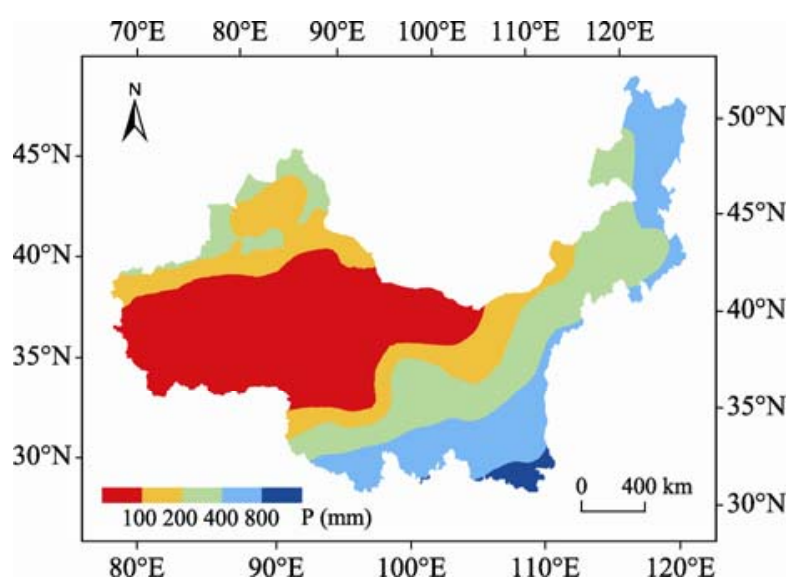

Fig. 6 The dry/wet climate zoning for China corresponding to precipitation $(P)$ the FC method. The climate in two specific regionsthe Ili area and the Horqin Sandy Land was highlighted to some extent, although it is not very ade-quate. There is a difference between precipitation and aridity indices. Contrary to aridity index, however, the boundaries have low consistency between precipitation and FC methods, and it is difficult for these boundaries to correspond to each other. It is also indicated that there are obvious discrepancies in dry/wet climate zoning between precipitation and aridity indices. When defining dry/wet climate zones by the previous classification thresholds, it is unavailable for the relatively consistent boundaries.

\section{Discussion and conclusions}

According to previous findings, dry/wet climate types commonly comprise extreme arid, arid, semiarid, subhumid and humid zones. Sometimes, it also includes dry sub-humid zone based on the further division on sub-humid zones. A fundamental question when defining the scope of arid areas is which types of climate zones are needed to adequately characterize arid areas. Therefore, it is necessary to identify the characteristics of aridity first. Heim (2002) indicated that aridity was defined in terms of low-average precipitation, available water, or humidity and, setting aside the possibility of climatic change, is a permanent climatic feature of a region. Paulo and Pereira (2006) defined aridity as a natural permanent imbalance in the water availability consisting in low average annual precipitation, with high spatial and temporal variability, resulting in overall low moisture and low carrying capacity of the ecosystems. It is thus clear that low precipitation and available water or moisture with a permanent feature in a region is the main performances of aridity. Accordingly, arid areas can be defined as dry/wet climate zones with low-average precipitation, available water, or humidity, correspondingly with high evapotranspiration, also with high spatial and temporal variability. Consequently, extreme arid, arid, semiarid and dry sub-humid zones were regarded as the categories of arid areas. The definition is in agreement with the research from UNEP, which was presented by Dregne (1991), and also coincides with the elaboration on combating drought and desertification from UNCCD (1994). The grade classification system of dry/wet climate zones in this paper is shown in Table 5. 
As a result, the scope of arid areas of NW China was defined as being localized to $31^{\circ} 33^{\prime}-49^{\circ} 11^{\prime} \mathrm{N}$, $73^{\circ} 28^{\prime}-119^{\circ} 54^{\prime} \mathrm{E}$. The geographical location was west to Xilingol League in Inner Mongolia, east to the western borders of Xinjiang, north to the northern foot of Qinling Mountains, south to the national boundary between China and Mongolia. Considering the integrity of administrative boundaries and convenience in regional management, we repeated that the boundaries of arid areas of NW China with Shaanxi-section and Inner Mongolia-section in Fig. 6. Besides, the border of Inner Mongolia-section is based on the under- standing of geographic convenience and alignment with major watersheds as well. It is considered the boundary between Northwest China and Northeast China, and lies at the edge of the farming-pastoral ecotone of Northern China (Liu et al., 2011). Consequently, the more detailed scope is is $3,800 \mathrm{~km}$ long from east to west and 2,100 km wide from north to south. It covers 390 counties in the whole area of Xinjiang, Qinghai, Gansu and Ningxia, Guanzhong Plain, north Shaanxi and the Inner Mongolia Plateau (Fig. 7). The total area is $3.74 \times 10^{6} \mathrm{~km}^{2}$, accounting for $39 \%$ of China.

Table 5 The grade classification system using F factor

\begin{tabular}{ccccccc}
\hline Classes & Extreme arid & Arid & Semiarid & Dry sub-humid & Sub-humid & Humid \\
\hline $\mathrm{F}$ & $<-1.0$ & $-1.0 \leq \mathrm{F}<0$ & $0 \leq \mathrm{F}<1.0$ & $1.0 \leq \mathrm{F}<1.25$ & $>1.25$ & $/$ \\
Aridity index & $\geq 16.0$ & $4.0 \leq \mathrm{AI}<16.0$ & $2.0 \leq \mathrm{AI}<4.0$ & $1.5 \leq \mathrm{AI}<2.0$ & $1.0 \leq \mathrm{AI}<1.5$ & $<1.0$ \\
\hline
\end{tabular}

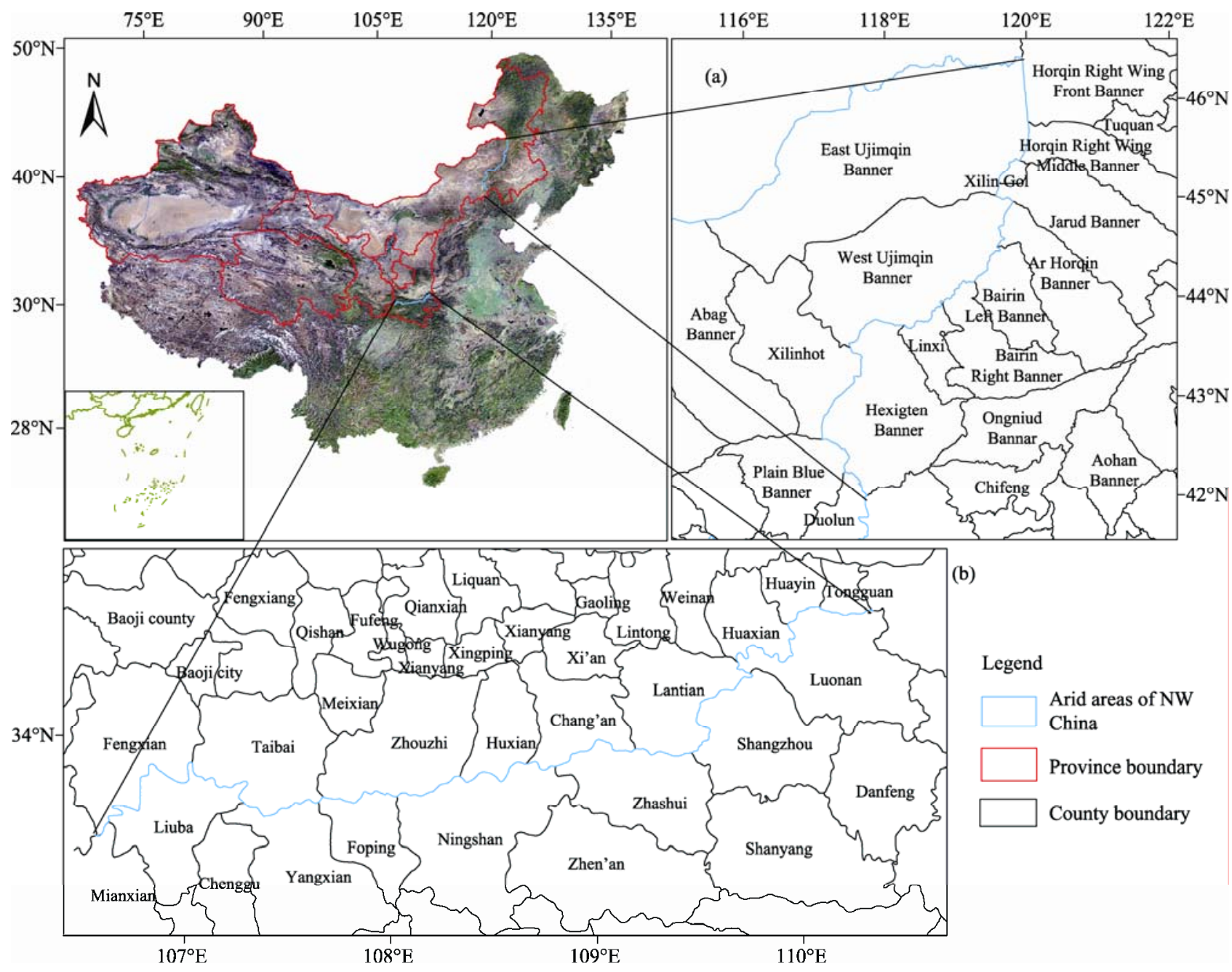

Fig. 7 The scope and distribution of arid areas of NW China ( $a$, eastern boundary area in the Inner Mongolia section; b, southern boundary area in Shaanxi section) 
In this paper, the FC method with a data-driven fashion was employed to classify dry/wet climate zones in NW China, and compared with two traditional indicators with the rule-driven strategy. The results indicated that the climate is wet in high mountain areas but relatively dry in the sandy plain area. Unique geographical regions can be identified effectively, such as the Ili area and Horqin Sandy Land. The demarcation lines among different climate regions mainly distribute along mountains and rivers. Divisional boundaries appeared to be greatly influenced by natural features or barriers between regions. The similar conclusion has been confirmed by Bieniek et al. (2012) that climate-division boundaries relied heavily on the major terrain features surrounding the grouped stations by applying cluster analysis. In addition, NW China is a meso-climatic region. Minor topographic variations can often cause great differences between one area and the next at this scale, as noted by Arias (1942). Therefore, it is influenced more easily by topographic features of the earth or large areas with different land conditions, such as extensive woods, swamps, deserts, etc, which further confirmed that the FC method is reasonable for the dry/wet climate zoning. Besides, the climate of a region or an area is the combination of different climate elements (Sahin and Cigizoglu, 2012). The FC approach contains different variables that might capture more overall information, so it can avoid the drawback with which climate conditions varied due to diverse natural landscape features. Therefore, it can be concluded that the FC method can perform better than any traditional single index for climate zoning in NW China.

However, one disadvantage needs to be noted that regionalization may not be easily reducible to a set of systematic classification rules, and thus, unlike the rule-driven strategy, it may not satisfy the desire or need to quantify climate types on the basis of statistical properties or mathematical formulae (Fovell, 1997). Our analysis also showed that two unique clusters (class 7 and class 2) by using FC method were isolated, which caused non-comparable information, and it is difficult to compare with the rules of two traditional indicators, and/or define a new climate type for it. In addition, we still need to refer to the traditional classifications when redefining the climate zones. Although classifications with predefined thresholds was partly subjective, they were on the basis of some important components of the ecosystem (e.g. alignment with major watersheds, agricultural administrative districts and geographic convenience) and expert experience, and thus have certain rationality and reference significance.

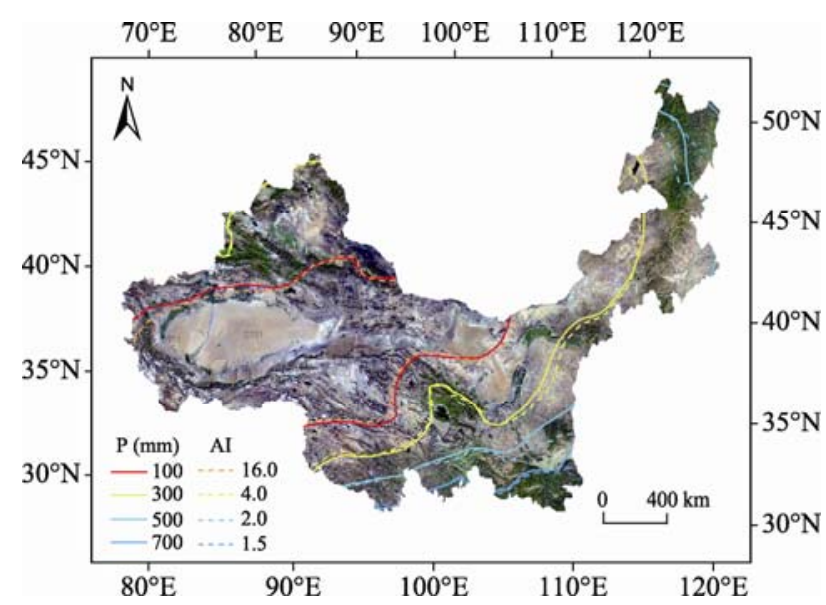

Fig. 8 The comparison of climate zoning between two traditional indicators after adjusting the classification thresholds of precipitation

When comparing two traditional indicators, we also found that there are great differences and low consistency for the boundaries of climate zones between them. It may be caused by the classification rules predefined by experts. However, it may also relate to climate change. As mentioned in the introduction, previous researches were mainly based on observed data before the 1980s. Significant changes in climate, however, have took place in NW China since then (Wang et al., 2004; Qian and Lin, 2005; Yang et al., 2008; Zheng et al., 2010). The precipitation moved and fluctuated to a certain extent. Therefore, the division boundary of dry/wet climate might change and migrate with time (Wu et al., 2002). The meteorological data used in the present paper is from the last 30 years (1981-2010), so that there are some differences between two classifications. For this reason, an attempt was made to adjust and update the classification thresholds of precipitation, and as a result, it is found that the division boundaries show a significant agreement between precipitation and aridity, as shown in Fig. 8. Accordingly, we can infer that climate change plays an important role in the dry/wet climate zoning. However, further studies are needed to understand the 
changed characteristics and patterns of dry/wet climate more explicitly under the background of global climate change. We also need to do more analysis and verification for the application of FC analysis in geographical regions at different scales (e.g. macro-scale). This paper performed an analysis on classifications of wet/dry climate in NW China by applying the FC method and defined the scope of arid areas of NW China. It is expected to provide a reference for further studies and understanding on arid areas of NW China.

\section{Acknowledgements}

This work was jointly supported by the Special Foundation of National Science \& Technology Supporting Plan (2011BAD29B09), the National Natural Science Foundation of China (31172039), the '111' Project from the Ministry of Education and the State Administration of Foreign Experts Affairs (B12007), the Supporting Project of Young Technology Nova of Shaanxi Province (2010KJXX-04) and the Supporting Plan of Young Elites and basic operational cost of research from Northwest A\&F University.

\section{References}

Abatzoglou J T, Redmond K T, Edwards L M. 2009. Classification of regional climate variability in the state of California. Journal of Applied Meteorology and Climatology, 48 (8): 1527-1541.

Ahmed B Y M. 1997. Climatic classification of Saudi Arabia-an application of factor-cluster analysis. Geo Journal, 41(1): 69-84.

Allen R G, Pereira L S, Raes D, et al. 1998. Crop evapotranspiration: guidelines for computing crop water requirements. FAO Irrigation and Drainage Paper 56. Food and Agriculture of the United Nations, Rome.

Arias A C. 1942. The classification of climate. Monthly Weather Review, 70(11): 249-253.

Bernardo S, Soares A A, Mantovani E C. 2006. Irrigation Manual, $6^{\text {th }}$ ed. Viçosa: UFV university press, 625.

Bieniek P A, Bhatt U S, Thoman R L, et al. 2012. Climate divisions for Alaska based on objective methods. Journal of Applied Meteorology and Climatology, 51(7): 1276-1289.

CAS, the Commission for geographical regionalization. 1959. The Climate Gegionalization in China. Beijing: Science Press.

Castillo-Rodríguez M, López-Blanco J, Muñoz-Salinas E. 2010. A geomorphologic GIS-multivariate analysis approach to delineate environmental units, a case study of La Malinche volcano (central México). Applied Geography, 30(4): 629-638.

Chen X J. 1982. A new approach to the climate division of China. Acta Meteorologica Sinica, 40: 35-48.

Dinpashoh Y, Fakheri-Fard A, Moghaddam M, et al. 2004. Selection of variables for the purpose of regionalization of Iran's precipitation climate using multivariate methods. Journal of Hydrology, 297(1-4): 109-123.

Dregne H, Kassas M, Rozanov B. 1991. A new assessment of the world status of desertification. Desertification Control Bulletin, 6-18.

Fang K Y, Gou X H, Chen F H, et al. 2009. Drought variations in the eastern part of northwest China over the past two centuries: evidence from tree rings. Climate Research, 38: 129-135.

Fovell R G. 1997. Consensus clustering of US temperature and precipitation data. Journal of Climate, 10(6): 1405-1427.

Fu C B, Ma Z G. 2008. Global change and regional aridification. Chinese Journal of Atmospheric Sciences, 32(4): 752-760.

Heim R R. 2002. A review of twentieth-century drought indices used in the United States. Bulletin of the American Meteorological Society: $1149-1165$.

Hisdal H, Tallaksen LM. 2003. Estimation of regional meteorological and hydrological drought characteristics: a case study for Denmark. Journal of Hydrology, 281(3): 230-247.

Huang B W. 1959. Draft of overall natural regionalization of China. Chinese Science Bulletin, 18: 594-602.

Kaiser H F, Rice J. 1974. Little Jiffy Mark. Educational and Psychological Measurement, 34: 111-117.

Kim J O, Mueller C W. 1978. Factor Analysis: Statistical Methods and Practical Issues. Sage: Sage University Paper Series in Quantitative Applications in the Social Sciences.

Kostopoulou E, Jones P D. 2007. Comprehensive analysis of the climate variability in the eastern Mediterranean. Part I: map-pattern classification. International Journal of Climatology, 27(9): 1189-1214.

Jacobeit J. 2010. Classifications in climate research. Physics and Chemistry of the Earth, Parts A/B/C, 35(9-12): 411-421.

Li S K. 1987. Agro-climatic regionalization of China. Journal of Nature Resources, 2: 71-83.

Li X Z, Liu X D, Ma Z G. 2004. Analysis on the drought characteristics in the main arid regions in the world since recent hundred-odd years. Arid Zone Research, 23(1): 45-54.

Liu J H, Gao J X, Lv S H, et al. 2011. Shifting farming-pastoral ecotone in China under climate and land use changes. Journal of Arid Environments, 75(3): 298-308.

Liu J G, Diamond J. 2005. China's environment in a globalizing world. Nature, 435: 1179-1186.

Logan K E, Brunsell N A, Jones A R, et al. 2010. Assessing spatio-temporal variability of drought in the U.S. central plains. Journal of Arid Environments, 74(2): 247-255.

Luo K F. 1954. Draft of natural geography regionalization of China. Acta Geographica Sinica, 20: 379-394.

Malekinezhad H, Nachtnebel H P, Klik A. 2011. Comparing the index-flood and multiple-regression methods using L-moments. Physics and Chemistry of the Earth, Parts A/B/C 36(1-4): 54-60.

Mishra A K, Singh V P. 2010. A review of drought concepts. Journal of Hydrology, 391(1-2): 202-216. 
Modarres R, Sarhadi A. 2011. Statistically-based regionalization of rainfall climates of Iran. Global and Planetary Change, 75(1-2): $67-75$.

Overall J E, Klett C J. 1972. Applied Multivariate Analysis. McGraw-Hill: New York.

Paulo A A, Pereira L S. 2006. Drought concepts and characterization. Water International, 31(1): 37-49.

Qian W H, Lin X. 2005. Regional trends in recent precipitation indices in China. Meteorology and Atmospheric Physics, 90(3-4): 193-207.

Qian W H, Qin A. 2007. Precipitation division and climate shift in China from 1960 to 2000. Theoretical and Applied Climatology, 93(1-2): $1-17$.

Ren M E, Yang R Z. 1961. Issues on physical regionalization in China. Acta Geographica Sinica, 27: 66-74.

Sahin S, Cigizoglu H K. 2012. The sub-climate regions and the sub-precipitation regime regions in Turkey. Journal of Hydrology, 180-189.

Shi Y F, Shen Y P, Kang E S, et al. 2006. Recent and Future Climate Change in Northwest China. Climatic Change, 80(3-4): 379-393.

Sun H G, Yu X. 2012. A research of regional difference in R\&D activities in Guangdong, PR China. Progress in Applied Mathematics, 3(1): 22-27.

Um M J, Yun H, Jeong C, et al. 2011. Factor analysis and multiple regression between topography and precipitation on Jeju Island, Korea. Journal of Hydrology, 410(3-4): 189-203.

Unal Y, Kindap T, Karaca M. 2003. Redefining the climate zones of Turkey using cluster analysis. International Journal of Climatology, 23(9): 1045-1055.

UNCCD, United Nations Convention to Combat Desertification.1994. Elaboration of an International Convention to Combat Desertification in Countries Experiencing Serious Drought and/or Desertification, Particularly in Africa. New York: UNCCD. [1997-2-11]. http://www.un.org.

UNEP. 1992. World Atlas of Desertification. London: Edward Arnold, 69.

Wang G, Cheng G. 2000. The characteristics of water resources and the changes of the hydrological process and environment in the arid zone of northwest China. Environmental Geology, 39(7): 783-790.

Wang L, Xie X Q, Li Y S, et al. 2004. Changes of humid index and borderline of wet and dry climate zone in northern China over the past 40 years. Geographical Research, 23: 45-54.
Wu S H, Yang Q Y, Zheng D. 2002. An index system for boundaries of eco-geographical regions of China. Progress in Geograpgy, 21: $302-310$.

Xi C F, Qiu B J, Zhang J M, et al. 1984. Principles and system of physical regionalization. In: the National Commission for Agricultural Regionalization. Outline of Physical Regionalization of China. Beijing: Science Press.

Yang G Y, Wang L, Wang H. 2010. Thinking of food security in China based on regional water resources and land cultivation. Transactions of the CSAE, 26(12): 1-5.

Yang Y Z, Feng Z M, Huang H Q, et al. 2008. Climate-induced changes in crop water balance during 1960-2001 in Northwest China. Agriculture, Ecosystems \& Environment, 127(1-2): 107-118.

Zhang B K, Duan Y W, Cao L. 1956. Draft of climate regionalization in China. In: Draft of Physical Regionalization in China. Beijing: Science Press.

Zhang D, Fengquan L, Jianmin B. 2000. Eco-environmental effects of the Qinghai-Tibet Plateau uplift during the Quaternary in China. Environmental Geology, 39(12): 1352-1358.

Zhang G L, Dong J W, Xiao X M, et al. 2012. Effectiveness of ecological restoration projects in Horqin Sandy Land, China based on SPOT-VGT NDVI data. Ecological Engineering, 38(1): 20-29.

Zhang J M. 2006. Study on temporal and spatial distribution of climate resource in Yili River Basin. Arid Meteorology, 24(2): 1-4.

Zhang J T, Li Z. 1999. A Study on demarcation indexes between sub humid and semiarid sectors in China. Progress in Geograpgy, 18: 230-237.

Zhang L Y, Su G W. 1993. Geneses, characteristics and environmental optimization of Northwest China's arid area. Journal of Arid Land Resources and Environment, 7(3-4): 1-10.

Zhang Q F, Wu F Q, Wang L. 2011. Application of PCA integrated with $\mathrm{CA}$ and GIS in eco-economic regionalization of Chinese Loess Plateau. Ecological Economics, 70(6): 1051-1056.

Zhao S Q. 1983. A new scheme for comprehensive geographical regionalization in China. Acta Geographica Sinica, 38: 1-10.

Zhao X, Tan K, Zhao S, et al. 2011. Changing climate affects vegetation growth in the arid region of the northwestern China. Journal of Arid Environments, 75 (10): 946-952.

Zheng J Y, Yin Y H, Li B Y, et al. 2010. A new scheme for climate regionalization in China. Acta Geographica Sinica, 65: 3-13. 